\title{
Myasthenia Gravis - A Review of Current Therapeutic Options
}

\author{
Saiju Jacob \\ Queen Elizabeth Neuroscience Centre, University Hospitals of Birmingham NHS Foundation Trust, Birmingham, UK
}

DOl: https://doi.org/10.17925/ENR.2018.13.2.86

$\mathrm{M}$ yasthenia gravis (MG) is an autoimmune disorder that leads to skeletal muscle weakness and fatigue. The autoimmune attack is caused by autoantibodies against the acetylcholine postsynaptic receptors at the neuromuscular junction of skeletal muscles. However, other antigenic targets that are components of the neuromuscular junction have also been implicated in the pathogenesis of MG. The current standard of care is immunosuppressive therapy; however, many existing therapeutic options have not been validated for use in MG in large randomised controlled trials. Furthermore, around 10\% of patients with generalised MG are refractory to treatment. The complement system is involved in numerous inflammatory, neurodegenerative and autoimmune diseases, and is a key factor in the pathogenesis of acetylcholine receptor antibody-related MG. Targeting complement and other components involved in the underlying pathogenesis of the disease may provide useful treatment options, particularly for refractory patients.

\section{Keywords}

Complement, refractory myasthenia gravis, acetylcholine receptor

Disclosure: Saiju Jacob reports receiving personal compensation from Alexion Pharmaceuticals, serving as an international advisory board member. Saiju Jacob is also an eculizumab-in-myasthenia-gravis-trial investigator.

Acknowledgements: Medical writing assistance, including preparation of the drafts under the guidance of the author, was provided by Katrina Mountfort, freelance writer for Touch Medical Media, and was supported by Touch Medical Media.

Review Process: Double-blind peer review.

Compliance with Ethics: This study involves a review of the literature and did not involve any studies with human or animal subjects performed by the author.

Authorship: The named author meets the International Committee of Medical Journal Editors (ICMJE) criteria for authorship of this manuscript, takes responsibility for the integrity of the work as a whole, and has given final approval for the version to be published.

open Access: This article is published under the Creative Commons Attribution Non-commercial License, which permits any non-commercial use, distribution, adaptation, and reproduction provided the original author and source are given appropriate credit. (C) The Author 2018.

Received: 14 February 2018

Accepted: 13 July 2018

Citation: European Neurological Review. 2018;13(2):86-92 Corresponding Author: Saiju Jacob, Neurology, University Hospitals Birmingham NHS Foundation Trust, Birmingham, B15 2TH. E: Saiju.Jacob@uhb.nhs.uk

Support: No funding was received for the publication of this article.
Myasthenia gravis (MG) is a relatively rare autoimmune disease, caused by an antibody-mediated blockade of neuromuscular transmission and resulting in skeletal muscle weakness. MG is characterised by fluctuating muscle weakness that worsens with activity and improves on resting. Over half of patients with MG initially present with ocular symptoms with or without generalised weakness. ${ }^{1-3}$ However, the disease progresses over weeks or months, with exacerbations and remissions. ${ }^{1}$ In the majority of patients, symptom onset to maximal weakness occurs within the first 2 years. ${ }^{3}$ While a number of immunosuppressive therapies are available, around $10 \%$ of patients with MG are termed refractory, experiencing frequent relapses upon lowering their immunotherapy or remaining clinically unstable on their current immunotherapeutic treatment regimen. ${ }^{4,5}$ This review article aims to discuss the current therapeutic options for MG and the potential of novel agents targeting the underlying pathogenesis of the disease.

\section{Pathophysiology of myasthenia gravis}

MG is the result of defective transmission between motor neurons and skeletal muscle. In around 80-90\% of generalised patients, this is due to autoantibody formation against the acetylcholine receptor (AChR). ${ }^{6}$ The antibody interferes with neuromuscular transmission via blockade of receptor sites by steric hindrance, destruction of AChRs, and crosslinking of AChR, which causes increased turnover by endocytosis (from 5-6 days to 2.5 days), resulting in a loss of receptor density. This is followed by focal lysis of the post-junctional membrane by the terminal component of complement (Figure 1). ${ }^{6}$ Around $50-70 \%$ of generalised MG patients who do not produce antibodies against AChR are seropositive for antibodies against the muscle-specific receptor kinase (MuSK), which mediates the clustering of AChRs during synapse formation and is essential for the formation and maintenance of the neuromuscular junction (NMJ). ${ }^{7.8}$ In the remaining cases, termed seronegative, antibodies against AChRs and MuSK cannot be detected by available radioimmune assays. ${ }^{8}$ Clustered AChR-antibodies, which have demonstrated pathogenicity and have the ability to activate complement, have been detected in more than half of patients with previously seronegative generalised MG. ${ }^{9},{ }^{90}$ Recently, immunoglobulin G (IgG)1 (and hence complement-fixing) antibodies against low-density lipoprotein receptor-related protein 4, which also is an essential component of the NMJ, have been found in a variable proportion of patients who were previously thought to be seronegative. ${ }^{11-13}$ Other autoantibodies to skeletal muscle proteins (titin, ryanodine receptor, myosin, actin, tropomyosin and troponin) have been found in the serum of MG patients, but their significance is not yet known., ${ }^{8,14}$

MG is considered a T-cell-dependent B-cell-mediated disease, in that CD4+ T-helper cells and T-regulatory cells facilitate the proliferation and differentiation of B-cells into AChR antibody-producing plasma cells, although they have additional different actions affecting the pathophysiology of MG..$^{15}$ The thymus gland, the central organ in T-cell mediated immunity, is also an important factor in the pathogenesis of MG with AChR autoantibodies. It undergoes structural changes that make it like a tertiary lymphoid organ; however, its role has not been elucidated fully. It is the primary site of production of autoantibodies, and undergoes structural and functional 
Figure 1: Pathogenic mechanism of anti-acetylcholine antibodies in myasthenia gravis

A Complement binding and activation at the NMJ

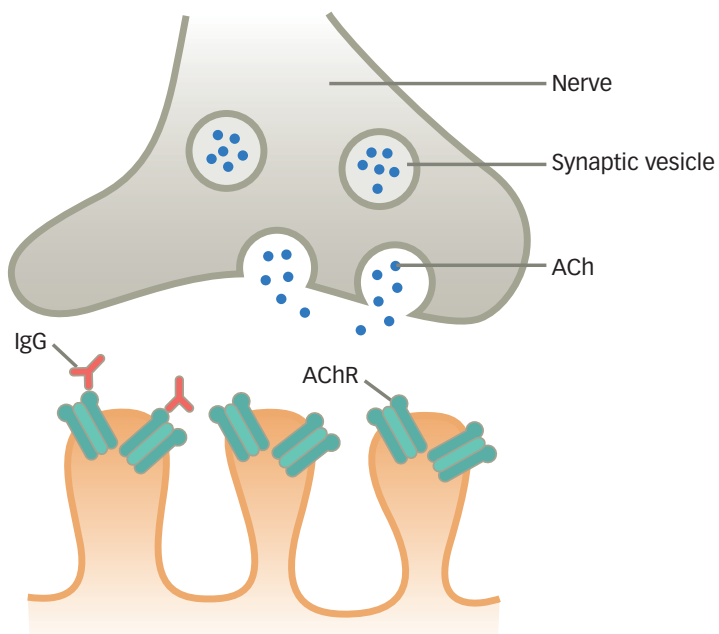

C Antigenic modulation

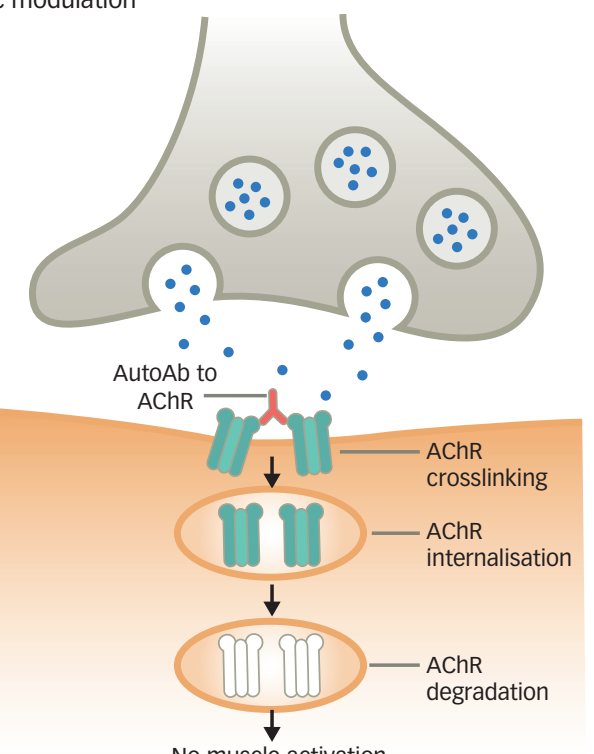

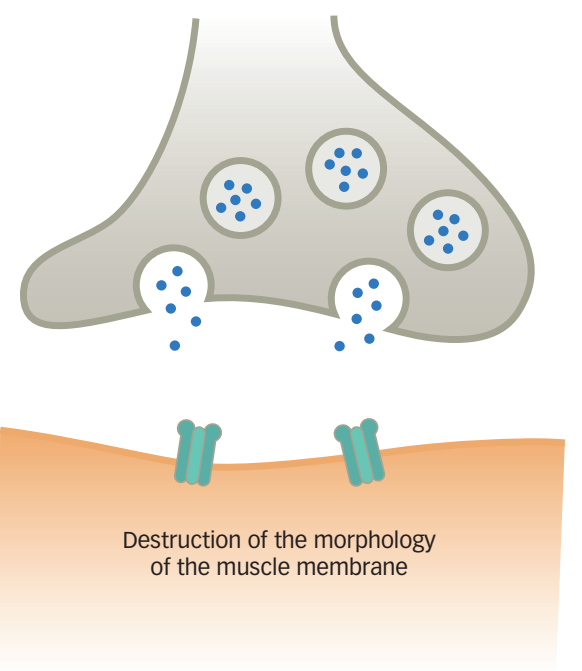

D Functional AChR block

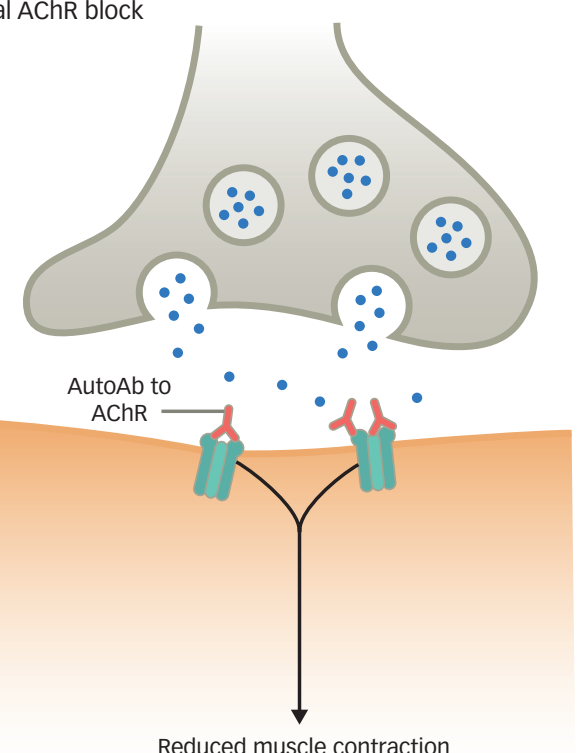

Antibodies bind to the AChR and activate the complement cascade, resulting in the formation of MAC and localised destruction of the postsynaptic NMJ membrane (A). This alters the morphology of the postsynaptic membrane of the NMJ of patients with myasthenia gravis, resulting relatively flat surface (B). Antibodies then cross-link AChR molecules on the NMJ postsynaptic membrane. These cross-linked AChR molecules are internalised and degraded, a process known as antigenic modulation, reducing the number of AChR molecules on the postsynaptic membrane (C). Finally, antibodies bind the ACh-binding sites of the AChR, causing functional block of the AChR by interfering with binding of ACh released at the NMJ (D). This results in failure of neuromuscular transmission and therefore reduced muscle contraction.

$A C h R=$ acetylcholine receptor; IgG = immunoglobulin $\mathrm{G} ; \mathrm{MAC}=$ membrane attack complex; NMJ = neuromuscular junction. Figure adapted from Conti-Fine et al. ${ }^{6}$

changes in $\mathrm{MG}$, and may be considered a tertiary lymphoid organ. ${ }^{16}$ Levels of thymic and peripheral blood CD4+CD25+ regulatory T-cells are reduced in patients with $\mathrm{MG}$, and this is correlated with disease severity.17

\section{The complement system and its role in myasthenia gravis}

The complement system is a component of the innate immune defence against infection and is an important driver of inflammation in patients with MG who produce antibodies against $A C h R .{ }^{18}$ It is strongly involved in the pathogenesis of $\mathrm{MG} .^{19}$ Excessive activation of complement can cause local and/or systemic inflammation, tissue damage and autoimmune disease. Immune complexes, indicative of a destructive autoimmune reaction involving the postsynaptic membrane in $\mathrm{MG}$, were first detected in the $1970 \mathrm{~s}^{20}$ Complement deposits at the NMJ are a characteristic finding of MG, suggesting that AChR antibody induces muscle weakness by complement pathway activation, resulting in the formation of membrane attack complex (MAC), or terminal complement complex. ${ }^{19}$ The binding of complement factors to the AChR autoantibody results in the generation of a number of biologically active products, including anaphylactic peptides $\mathrm{C} 3 \mathrm{a}$ and $\mathrm{C} 5 \mathrm{a}$, opsonic fragments $\mathrm{C} 3 \mathrm{~b}$ and C4b, and the MAC (which comprises C5b, C6, C7, C8 and C9). Any of these may contribute to the pathology of MG. ${ }^{18}$ The complement system is an attractive therapeutic target, as it is well characterised, has many natural inhibitors, and has a number of receptors that bind to activation fragments. ${ }^{21}$ However, treatment must impair complement deposition without detriment to the adaptive immune system. 


\section{Current therapeutic strategies in the management of myasthenia gravis}

There are a number of current therapeutic strategies for MG, although no single regimen is appropriate for all patients, and treatment must be individualised. " These include: acetylcholinesterase inhibitors, corticosteroids, other immunosuppressant drugs, thymectomy, and immunomodulatory therapies.

\section{Acetylcholinesterase inhibitors}

Acetylcholinesterase inhibitors have been used in MG for almost a century, and include pyridostigmine, neostigmine and ambenonium chloride. ${ }^{1}$ Pyridostigmine is recommended as part of the initial treatment in most patients with MG and is often used as maintenance therapy. ${ }^{22,23}$ They provide temporary (and often incomplete) relief of symptoms. Their efficacy is so clear that it would be ethically unjustifiable to perform a randomised controlled trial; although, their use does not affect disease progression from a pathological point of view. ${ }^{24}$ However, a proportion of patients (especially with purely ocular symptoms) would not require any other immunomodulatory treatment except the cholinesterase inhibitors.

\section{Corticosteroids}

Corticosteroids were the first immunosuppressant drugs to be used in $\mathrm{MG}$ and are recommended in patients whose symptoms persist despite treatment with pyridostigmine..22,23 The most commonly used corticosteroid in MG is prednisolone. However, corticosteroids are associated with serious side effects, especially with long-term usage. ${ }^{1,25}$ Nevertheless, as a result of their low cost and efficacy, corticosteroids remain the mainstay of treatment in MG around the world, which is supported by observational studies and expert opinion. ${ }^{26}$

\section{Other immunosuppressant drugs}

Azathioprine, which inhibits purine metabolism, as well as T- and B-cell production, is the steroid-sparing immunosuppressant drug that has been most used in MG. ${ }^{1}$ It improves weakness in most patients, but the benefit may not be apparent for 6-12 months. ${ }^{1}$ In a randomised controlled trial $(n=34)$ of prednisolone plus azathioprine versus prednisolone plus placebo, there was no difference between the treatment groups until after 12 months. ${ }^{27}$ However, the same study showed that after 24-36 months, the relapse rate was lower with reduced steroid dosages, and there were longer remissions and fewer side effects in the azathioprine group. Its use is associated with hepatotoxicity and myelosuppression in around $15 \%$ and $9 \%$ of patients, respectively. ${ }^{28}$

Methotrexate is a commonly used alternative to azathioprine. There is some evidence for its effectiveness in MG, with one study showing that it is probably as effective as azathioprine as a steroid-sparing agent after 10 months. ${ }^{29}$ However, in a randomised controlled trial $(n=50)$, methotrexate did not give any steroid-sparing benefit, and did not improve secondary measures of MG compared to placebo over 12 months. $^{30}$

Cyclosporine is mainly used in patients in whom azathioprine is not tolerated and has been shown to improve muscle strength and reduce antibody levels, but it is also associated with side effects (35\% discontinuation rate, of which $10 \%$ with renal toxicity), limiting its widespread use. ${ }^{31}$

Mycophenolate mofetil (MMF), which inhibits guanosine nucleotide synthesis and selectively inhibits activated T-cells, has a more favourable side effect profile than azathioprine. ${ }^{32}$ From 1998, when its use for MG was first reported, until 2008, MMF was considered an effective treatment option. ${ }^{33}$ A small study $(n=5)$ found that MMF was effective and well tolerated as an adjunctive immunosuppressive therapy in patients with refractory MG. ${ }^{34}$ In 2008, two phase III studies did not demonstrate the superiority of MMF over placebo. ${ }^{35,36}$ However, in 2016, a retrospective cohort study found that discontinuation/marked reduction of MMF therapy may substantially increase the risk of MG exacerbation, supporting the commonly held view that MMF has a role to play in the maintenance of MG remission. ${ }^{37}$

Tacrolimus, which inhibits interleukin- (IL-)2, has shown some benefit in low doses and may be useful as a steroid-sparing agent, although evidence in support of its use is currently limited. ${ }^{38-40}$

It is clear from the above discussion that several immunosuppressive medications are moderately effective as steroid-sparing drugs in MG, but their onset of action may be delayed, the effect may not be sustained and very often their use is limited by severe side effects.

\section{Thymectomy}

Therapeutic ablation of the thymus gland (thymectomy) has been routinely performed in MG for more than 75 years. Thymectomy has been beneficial in numerous small case studies of carefully selected refractory MG patients. ${ }^{41-44}$ In addition, there are a number of clinically meaningful reports on large series of thymectomised patients but with widely varying rates of clinical improvement or remission. ${ }^{45-48}$ A systematic review found numerous methodologic flaws that prevented definite conclusions from being drawn regarding the benefits of thymectomy in patients with nonthymomatous MG. ${ }^{49}$ A randomised clinical trial $(n=126)$ investigating the efficacy and safety of thymectomy was conducted in 2016.50 Patients were randomly assigned to extended transsternal thymectomy plus alternate-day prednisone or alternate-day prednisone alone. Patients who underwent thymectomy had a lower average Quantitative Myasthenia Gravis score over a 3-year period than those who received prednisone alone (6.15 versus $8.99, p<0.001$ ). Patients in the thymectomy group also had a lower requirement for alternate-day prednisone. Fewer patients in the thymectomy group than in the prednisone-only group required immunosuppression with azathioprine (17\% versus $48 \%, p<0.001)$ or were hospitalised for exacerbations ( $9 \%$ versus $37 \%, p<0.001$ ). The incidence of treatment-associated complications did not differ significantly between the two groups, but patients in the thymectomy group had fewer treatment-associated symptoms related to immunosuppressive medications $(p<0.001)$ and lower levels of distress related to symptoms ( $p=0.003$ ). The investigators concluded that, over 3 years, thymectomy improved clinical outcomes and reduced the need for immunosuppressive therapy in patients with nonthymomatous MG. ${ }^{50}$

Further clinical trials are needed to ascertain the subset of patients who are most likely to benefit from the procedure. The effects of thymectomy are not immediate, and remissions may occur years later. It is also not known when it is the optimum time to perform thymectomy. However, thymectomy appears to be a reasonable therapeutic option in patients with generalised myasthenia and positive AChR antibodies and in any patient with a radiologically suspected thymoma.

\section{Immunomodulatory therapies}

Immunomodulatory therapy such as plasma exchange and intravenous immunoglobulin (IVIg) can be useful in acute MG exacerbations, ${ }^{51,52}$ and are widely used as the first-line treatments in myasthenic crisis. Both are useful techniques in the management of $\mathrm{MG}$, but plasma exchange 


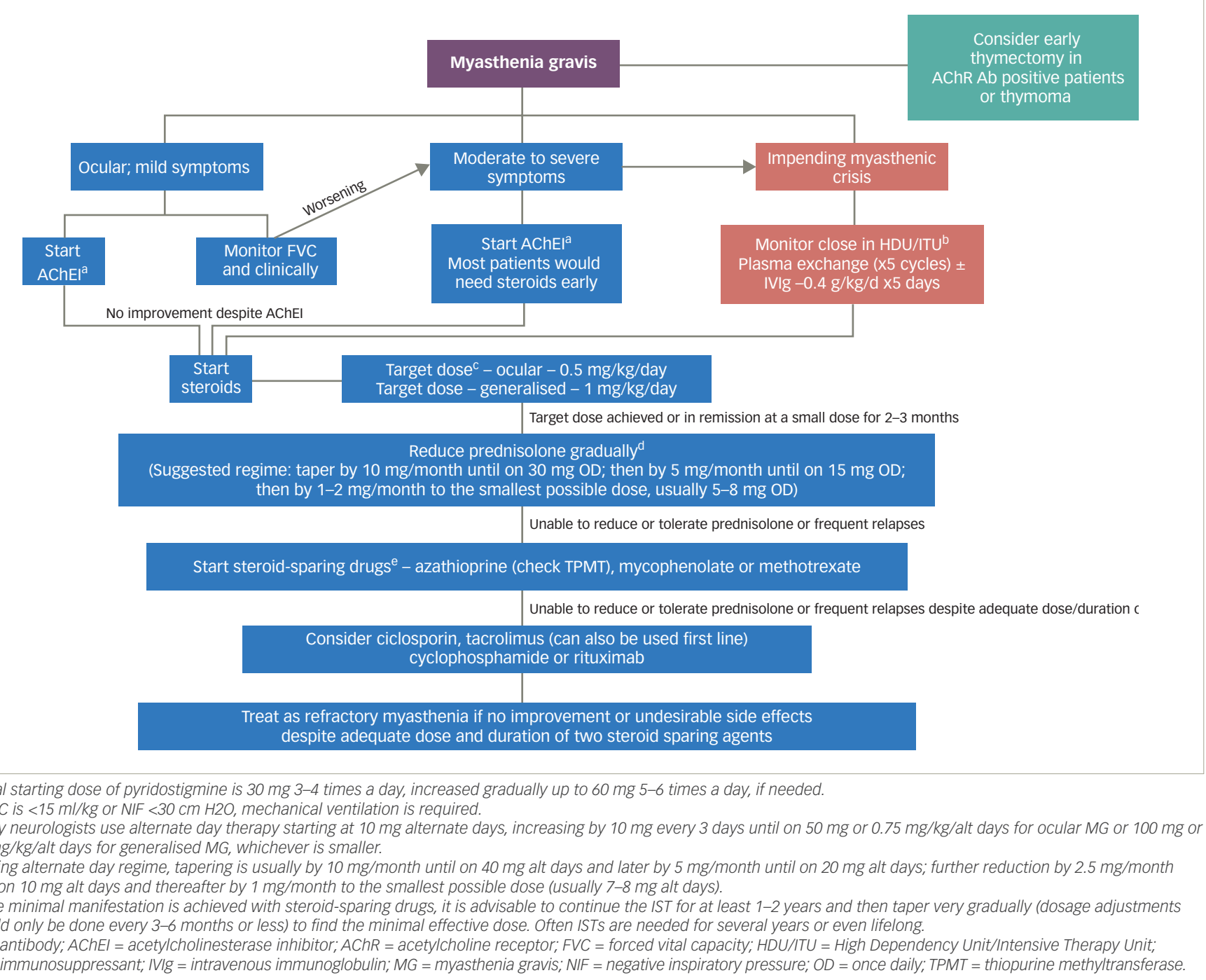

may need invasive central line insertions and can lead to potential complications. IVIg use can be limited due to supply issues, since this is a human-blood-derived product. These two therapies still remain the mainstay in patients with severe exacerbations causing bulbar muscle weakness, with or without ventilatory support.

In summary, there are several established and effective therapies for MG but mosthave not been tested using robust randomised controlled trials, or their efficacy has not been demonstrated in chronic or refractory MG. Attempts to perform clinical trials in MG have also been impaired by low patient recruitment or inconsistencies in clinical trial design, leading to the 2012 recommendations by the Medical Scientific Advisory Board of the Myasthenia Gravis Foundation of America (MGFA) for future clinical trials. These included the use of a quantitative measures, such as the MG-Composite, that is weighted for clinical significance and incorporates patient-reported outcomes, consideration of alternative strategies for assessment of efficacy and safety, and development of predictive biomarkers..$^{53}$

\section{Practical management of myasthenia gravis}

A proposed treatment algorithm is given in Figure 2. In patients with ocular or mild generalised myasthenia, the initial treatment is with cholinesterase inhibitors. If there is no significant response to cholinesterase inhibitors, most neurologists will commence treatment with steroids. The usual target dose of prednisolone is up to $0.5 \mathrm{mg} / \mathrm{kg} /$ day for pure ocular myasthenia and up to $1 \mathrm{mg} / \mathrm{kg} / \mathrm{day}$ for generalised myasthenia, if using a daily regime. Some authors recommend alternatedaydosingwithatargetofo. $75 \mathrm{mg} / \mathrm{kg} /$ alternatedaysforocularand $1.5 \mathrm{mg} / \mathrm{kg}$ /alternate days for generalised patients. ${ }^{23}$ If symptoms are fully under control or the target dose is reached (whichever is earlier), the corticosteroids are usually continued for 2-3 months followed by gradual tapering to the smallest possible dose. The tapering regime may have to be tailored to the individual patient, but usually involves reducing by $10 \mathrm{mg} / \mathrm{month}$ until on $30 \mathrm{mg} /$ day and thereafter by $5 \mathrm{mg} / \mathrm{month}$ until on $15 \mathrm{mg} /$ day. Further reductions are usually in steps of $1-2 \mathrm{mg} / \mathrm{month}$ to the smallest possible maintenance dose, usually around 5-8 mg/day. If the maintenance dose of steroids is more than 7-10 mg of prednisolone/day or if the initial episode is very severe, most specialists commence steroid-sparing agents like azathioprine as mentioned earlier. Thymectomy should be considered as outlined above. There is increasing usage of early thymectomy by many MG experts, especially when they are AChR-antibody positive with generalised symptoms. Plasma exchange and IVIgs are usually reserved for patients who are at risk of, or in, myasthenic crisis.

\section{Management of refractory myasthenia gravis}

For patients in whom immunosuppressant therapy is not tolerated or not effective, there is no clear guidance on which therapy should 
Table 1: Current approaches to the management of refractory myasthenia gravis

\begin{tabular}{|c|c|c|c|}
\hline Approach & Therapy & Mechanism of action & Limitations \\
\hline $\begin{array}{l}\text { Modulation of neuromuscular } \\
\text { cholinesterase inhibitors, prolong } \\
\text { ACh activity transmission }\end{array}$ & $\begin{array}{l}\text { Cholinesterase inhibitors: } \\
\text { pyridostigmine, neostigmine } \\
\text { and ambenonium chloride }{ }^{1,24}\end{array}$ & Prolong ACh activity & $\begin{array}{l}\text { Concern about the need for individualised } \\
\text { dosing, long-term efficacy and side effects. } \\
\text { Do not affect disease progression }\end{array}$ \\
\hline \multirow[t]{3}{*}{ Immunomodulation } & Thymectomy ${ }^{50}$ & Multiple effects & Invasive \\
\hline & Plasma exchange ${ }^{52}$ & Removal of antibodies & Data lacking on long-term effects \\
\hline & IVlg51 & Removal of antibodies & Data lacking on long-term effects \\
\hline \multirow[t]{5}{*}{ Immunosuppression } & Prednisone ${ }^{26}$ & Multiple effects & Side effects \\
\hline & Azathioprine $^{5}$ & Inhibits T- and B-cell proliferation & Limited data \\
\hline & Cyclosporine, tacrolimus 6,31 & Blocks T-cell activation and growth & Limited data, side effects \\
\hline & $\mathrm{MMF}^{35,36}$ & $\begin{array}{l}\text { Inhibits guanosine nucleotide synthesis and } \\
\text { selectively inhibits activated T-cells }\end{array}$ & Limited efficacy in some studies \\
\hline & Methotrexate ${ }^{29}$ & Multiple effects & Limited evidence \\
\hline
\end{tabular}

ACh = acetylcholine; $A C h R=$ acetylcholine receptor; IVIg = intravenous immunoglobulin; $M G$ = myasthenia gravis; $M$ MF = mycophenolate mofetil; MuSK = muscle-specific tyrosine kinase. Adapted from Conti-Fine et al. ${ }^{6}$

be given (Table 1). Current MGFA guidelines recommend the use of azathioprine, cyclosporine, MMF, methotrexate, tacrolimus, chronic IVIg or plasma exchange, cyclophosphamide, or rituximab, but acknowledge that evidence for these therapies are lacking. ${ }^{22}$ Small studies of patients with refractory MG have demonstrated beneficial effects of high-dose cyclophosphamide, effectively 'rebooting' the immune system while leaving the haematopoietic precursors intact. ${ }^{54,55}$ However, these effects are often short-lived. ${ }^{54}$ Furthermore, cyclophosphamide is associated with a high risk of side effects. Isolated cases of autologous haematopoietic stem cell transplant, which resulted in long-term remission of refractory MG have also been reported. ${ }^{56,57}$

Rituximab is an IgG1 kappa monoclonal antibody that depletes B-cells by binding to their CD20 molecule and initiating complement-dependent cytolysis or antibody-dependent cell-mediated cytotoxicity. ${ }^{58} \mathrm{~A}$ number of small case studies/isolated case reports have suggested that rituximab is effective, well tolerated and produces durable responses in the management of refractory MG. ${ }^{459-66}$ In a recent retrospective case series $(n=16)$, all patients achieved complete stable remission, pharmacologic remission or minimal manifestations of $\mathrm{MG}$, and $44 \%$ of patients remained relapse-free with a mean follow-up of 47 months (range, 18-81) since the last rituximab treatment. ${ }^{66}$ Rituximab appears to be most beneficial in MuSK antibody-positive individuals. ${ }^{67}$ In a multicentre, blinded, review $(n=199) 58 \%$ of anti-MuSK-positive patients with MG treated with rituximab reached the primary outcome of Myasthenia Gravis Status and Treatment Intensity level $\leq 2$, compared with $16 \%$ of those not treated with rituximab This study provides Class IV evidence that for patients with anti-MuSK MG, rituximab increased the probability of a favourable outcome. ${ }^{68}$ While the evidence base for the use of rituximab continues to grow, and guidelines recommend that it may be considered in refractory disease, no consensus has yet been reached. ${ }^{22}$

\section{Targeting the complement system}

Targeting the complement system offers a useful therapeutic alterative for MG.6.18,69 Many complement inhibitors have been shown to reduce the incidence and severity of experimental autoimmune MG without causing substantial toxicity or alteration of immune function. ${ }^{69}$ The most successful strategy to date has been the use of an anti-C5 antibody. ${ }^{70,71}$ Blockade of the complement pathway at C5 halts the production of the pro-inflammatory and pro-thrombotic C5a and C5b molecules, which are important for inflammatory cell chemotaxis and activation of the MAC. ${ }^{72}$ Furthermore, this does not impair the immunoprotective and immunoregulatory functions of the proximal cascade.

The antibody-based C5 inhibitor eculizumab (Soliris ${ }^{\oplus}$; Alexion Pharmaceuticals Inc., New Haven, CT, US) has been shown to be of potential use for MG treatment.73 In August 2017, the European Commission approved the extension of the current labelling indication for eculizumab to include the treatment of refractory generalised MG in adults who are anti-AChR antibody-positive. ${ }^{74}$ The US Food and Drug Administration (FDA) approval is for adults with generalised $\mathrm{MG}^{75}$ Although the phase III Safety and Efficacy of Eculizumab in Refractory Generalized Myasthenia Gravis (REGAIN) study and its long-term open-label extension study (MG-302) did not achieve statistical significance in their primary endpoint of change from baseline in Myasthenia Gravis-Activities of Daily Living Profile (MG-ADL) total score, a secondary data analysis suggested beneficial effects of eculizumab in refractory MG patients in 18 of 22 pre-defined endpoints across four separate scales of disease severity. ${ }^{76}$

Complement inhibitors have the potential to cause opportunistic infections since they impair the function of the major host defence mechanism against invading pathogens. ${ }^{69}$ The labelling information for eculizumab includes the recommendation for meningococcal vaccination in patients with complement deficiencies. ${ }^{74}$ No meningococcal infections were reported in the REGAIN study.7 As mentioned above, the complement system is not significantly involved in the pathogenesis of MuSK-MG and hence the use of eculizumab is currently limited to AChR antibody-positive myasthenia patients.

\section{Future therapeutic approaches}

In addition to the limitations detailed previously, all current therapies for MG are non-specific and focus on the activity of T- and B-cells. However, novel immunotherapies are in clinical development, including a variety of T-cell directed monoclonal antibodies that 
block the intracellular cascade associated with T-cell activation, monoclonal antibodies directed against key B-cell molecules, and inhibitors of complement, cytokines and transmigration molecules. Early reports of the proteasome inhibitor bortezomib indicate promising efficacy in MG: it reduced anti-AChR antibody titers, inhibited damage to the postsynaptic muscle membrane, and resulted in clinical improvement. ${ }^{77}$ Belimumab, which binds to soluble B-cell activating factor and reduces B-cell activation and differentiation into antibody-producing plasma cells, ${ }^{78}$ has been evaluated in MG (NCT01480596).

Increasing evidence suggests that Th17 immune reactions play an important role in MG, and cytokines such as IL-17 and IL-6 may represent attractive therapeutic targets. 79,80 Toclizumab, a humanised monoclonal antibody targeting the IL-6 receptor, has been found to be beneficial in cases of MG that did not respond to rituximab. ${ }^{81}$ Several human monoclonal antibodies against IL-17 are also in development, including brodalumab, ixekizumab and secukinumab, but these have not yet been tested in patients with MG. ${ }^{82}$

A potential adjunctive approach to MG is targeting muscle contractility. Tirasemtiv, a selective fast skeletal muscle troponin activator, binds to skeletal muscle troponin, thereby sensitising the muscle to calcium and ultimately improving muscle strength under submaximal stimulation. Results of a small $(n=32)$, short-duration clinical trial suggest that tirasemtiv may improve muscle function in MG. ${ }^{83}$ Additional studies are needed to demonstrate efficacy in $M G$ and determine optimal dosing. Short-term treatment with the $\beta 2$ adrenergic agonist albuterol was shown to improve weakness in a mouse model of anti-MuSK MG. ${ }^{84}$ 3,4-diaminopyridine, which enhances AChR release at the motor nerve terminal, has also shown promise in MUSK MG. ${ }^{85}$

Other potential approaches aim to target the anti-AChR autoimmune response and re-establish immune tolerance to the AChR. Possible approaches include administration of AChR or a portion of its sequence in a manner known to induce tolerance (e.g. oral or nasal); and disrupting the formation of the complex between major histocompatibility complex class II molecules, epitope peptide, T-cell receptor and CD4 molecule. ${ }^{6}$ However, these approaches have not progressed beyond the experimental stages. ${ }^{6}$

\section{Summary and concluding remarks}

The current standard of care in MG consists largely of generalised immunosuppression, which lacks specificity and selectivity. Currently approved therapies have a limited impact on refractory disease and around $10 \%$ of patients either fail to respond to treatment or suffer intolerable side effects. For such patients, there is a need for more aggressive treatment or treatment specifically directed to the underlying pathogenesis of the disease in order to prevent life-threatening crises, restore muscular strength and improve quality of life. Since there is a lack of clinical trial data, there is a need for registries to assess the effectiveness of the various therapeutic options. The MGFA has created a patient registry to promote research, treatment, advocacy and public awareness of MG (www.myasthenia.org).

The development of new, targeted therapies may help to improve quality of life in treatment-refractory patients. Disease heterogeneity in MG suggests that future therapeutic approaches should be tailored to MG subtype. Complement activation is an important contributor to the pathophysiology of MG and destruction of the NMJ; it is an attractive therapeutic target for the future. However, the utility of this approach will depend on the effect of complement inhibitors on the systemic immune system. Other novel therapeutic agents targeting the immunopathologic pathway underlying MG are also emerging. With the emergence of a number of potential therapies, there will be a need to develop biomarkers, which may help to effectively identify agents appropriate for later-phase testing. $\square$
1. Silvestri NJ, Wolfe GI. Myasthenia gravis. Semin Neurol. 2012;32:215-26

2. National Institutes of Health $(\mathrm{NIH})$. Myasthenia gravis fact sheet. Available at: www.ninds.nih.gov/Disorders/PatientCaregiver-Education/Fact-Sheets/Myasthenia-Gravis-Fact-Sheet (accessed 8 August 2017).

3. Grob D, Brunner N, Namba T, et al. Lifetime course of myasthenia gravis,

Sudulagunta SR, Sepehrar M, Sodalagunta MB, et al. Refractory myasthenia gravis - clinical profile, comorbidities and response myasthenia gravis - clinical profile, comor

5. Silvestri NJ, Wolfe GI. Treatment-refractory myasthenia gravis. J Silvestri NJ, Wolfe GI. Treatment-refracto
Clin Neuromuscul Dis. 2014;15:167-78.

6. Conti-Fine BM, Milani M, Kaminski HJ. Myasthenia gravis: past, present, and future. J Clin Invest. 2006;116:2843-54.

7. Hoch W, McConville J, Helms S, et al. Auto-antibodies to the receptor tyrosine kinase MuSK in patients with myasthenia gravis without acetylcholine receptor antibodies. Nat Med. 2001; 7:365-8

8. Meriggioli MN, Sanders DB. Muscle autoantibodies in myasthenia gravis: beyond diagnosis? Expert Rev Clin Immunol. 2012;8:427-38.

9. Leite MI, Jacob S, Viegas S, et al. IgG1 antibodies to acetylcholine receptors in 'seronegative' myasthenia gravis. Brain. 2008:131:1940-52.

10. Jacob $S$, Viegas $S$, Leite Ml, et al. Presence and pathogenic relevance of antibodies to clustered acetylcholine recepto relevance of antibodies to clustered acetylcholine receptor in ocular and gener.

11. Higuchi $\mathrm{O}$, Hamuro J, Motomura M, et al. Autoantibodies to low-density lipoprotein receptor-related protein 4 in myasthenia gravis. Ann Neurol. 2011;69:418-22.

12. Pevzner A, Schoser B, Peters K, et al. Anti-LRP4 autoantibodies in AChR- and MuSK-antibody-negative myasthenia gravis. J Neurol. 2012;259:427-35.

13. Zhang B, Tzartos IS, Belimezi M, et al. Autoantibodies to lipoprotein-related protein 4 in patients with double-seronegative myasthenia gravis. Arch Neurol. 2012;69: $445-51$.

14. Romi F, Skeie GO, Aarli JA, et al. Muscle autoantibodies in subgroups of myasthenia gravis patients. I Neurol. in subgroups of $\mathrm{m}$.

15. Milani $\mathrm{M}$, Ostlie $\mathrm{N}$, Wu H, et al. $\mathrm{CD} 4+\mathrm{T}$ and $\mathrm{B}$ cells cooperate in the immunoregulation of experimental autoimmune myasthenia gravis. J Neuroimmunol. 2006;179:152-62.

6. Weiss JM, Cufi P, Le Panse R, et al. The thymus in autoimmune myasthenia gravis: paradigm for a tertiary lymphoid organ. $R e$ Neurol (Paris). 2013;169:640-9.

17. Alahgholi-Hajibehzad M, Kasapoglu P, Jafari R, et al. The role of $T$ regulatory cells in immunopathogenesis of myasthenia gravis: implications for therapeutics. Expert Rev Clin Immunol. 2015;11:859-70.

18. Kusner LL, Kaminski HJ, Soltys J. Effect of complement and its regulation on myasthenia gravis pathogenesis. Expert Rev Clin regulation on myasthen
Immunol. 2008:4:43-52.

19. Tuzun E, Christadoss P. Complement associated pathogenic mechanisms in myasthenia gravis. Autoimmun Rev. 2013;12:904-11.

20. Engel $A G$, Lambert EH, Howard FM. Immune complexes (IgG and C3) at the motor end-plate in myasthenia gravis: ultrastructural and light microscopic localization and electrophysiologic correlations. Mayo Clin Proc. 1977; $52: 267-80$.

21. Morgan BP, Harris CL. Complement, a target for therapy in inflammatory and degenerative diseases. Nat Rev Drug Discov. 2015;14:857-77.

22. Sanders DB, Wolfe GI, Benatar M, et al. International consensus guidance for management of myasthenia gravis: executive summary. Neurology. 2016;87:419-25.

23. Sussman J, Farrugia ME, Maddison $P$, et al. Myasthenia gravis: Association of British Neurologists' management guidelines. Pract Neurol. 2015;15:199-206.

24. Mehndiratta MM, Pandey S, Kuntzer T. Acetylcholinesterase inhibitor treatment for myasthenia gravis. Cochrane Database Syst Rev. 2014;CD006986.

25. Peppa M, Krania M, Raptis SA. Hypertension and other morbidities with Cushing's syndrome associated with corticosteroids: a review. Integr Blood Press Control. 2011;4:7-16.

26. Schneider-Gold C, Gajdos P, Toyka KV, et al. Corticosteroids for myasthenia gravis. Cochrane Database Syst Rev 2005;CD002828.

27. Palace J, Newsom-Davis J, Lecky B. A randomized double-blind trial of prednisolone alone or with azathioprine in myasthenia gravis. Myasthenia Gravis Study Group. Neurology. 1998; 50:1778-83.
28. Jack KL, Koopman WJ, Hulley D, et al. A review of azathioprine-associated hepatotoxicity and myelosuppression in myasthenia gravis. J Clin Neuromuscul Dis. 2016;18:12-20

29. Heckmann JM, Rawoot A, Bateman K, et al. A single-blinded tria of methotrexate versus azathioprine as steroid-sparing agents in generalized myasthenia gravis. BMC Neurol. 2011:11:97.

30. Pasnoor $\mathrm{M}, \mathrm{He} J$ Herbelin L et al A randomized controlled trial of methotrexate for patients with generalized myasthen gravis. Neurology. 2016:87:57-64.

31. Tindall RS, Phillips JT, Rollins JA, et al. A clinical therapeutic trial of cyclosporine in myasthenia gravis. Ann N Y Acad SCi. 1993;681:539-51.

32. Cahoon WD, Jr., Kockler DR. Mycophenolate mofetil treatment of myasthenia gravis. Ann Pharmacother. 2006;40:295-8.

33. Heatwole C, Ciafaloni E. Mycophenolate mofetil for myasthenia gravis: a clear and present controversy. Neuropsychiatr Dis Treat. 2008;4:1203-9.

34. Prakash KM, Ratnagopal P, Puvanendran K, et al. Mycophenolate mofetil - as an adjunctive immunosuppressive therapy in refractory myasthenia gravis: the singapore experience. J Clin Neurosci. 2007:14:278-81.

35. Sanders DB, Hart IK, Mantegazza R, et al. An international, phase III, randomized trial of mycophenolate mofetil in myasthenia gravis. Neurology. 2008:71:400-6.

36. Group MS. A trial of mycophenolate mofetil with prednisone as initial immunotherapy in myasthenia gravis. Neurology. 2008:71:394-9.

37. Oskarsson B, Rocke DM, Dengel K, et al. Myasthenia gravis exacerbation after discontinuing mycophenolate: a single-center cohort study. Neurology. 2016;86:1159-63.

38. Cruz JL, Wolff ML, Vanderman AJ, et al. The emerging role of tacrolimus in myasthenia gravis. Ther Adv Neurol Disord. 2015;8:92-103.

39. Ponseti JM, Gamez J, Azem J, et al. Tacrolimus for myasthenia gravis: a clinical study of 212 patients. Ann N Y Acad SCI. 2008;1132:254-63

40. Yoshikawa H, Kiuchi T, Saida T, et al. Randomised, double-blind, placebo-controlled study of tacrolimus in myasthenia gravis. Neurol Neurosurg Psychiatry. 2011;82:970-7.

41. Miller RG, Filler-Katz A, Kiprov D, et al. Repeat thymectomy in chronic refractory myasthenia gravis. Neurology. chronic refractory

42. Ng JK, Ng CS, Underwood MJ, et al. Does repeat thymectomy 
improve symptoms in patients with refractory myasthenia gravis? Interact Cardiovasc Thorac Surg. 2014;18:376-80.

43. Pompeo E, Nofroni I, lavicoli N, et al. Thoracoscopic completion thymectomy in refractory nonthymomatous myasthenia. Ann rac Surg. 2000:70:918-23.

44. Zielinski M, Kuzdzal J, Staniec B, et al. Extended rethymectomy in the treatment of refractory myasthenia gravis: original video-assisted technique of resternotomy and results of the treatment in 21 patients. Interact Cardiovasc Thorac Surg. 2004;3:376-80.

45. Spillane J, Hayward M, Hirsch NP, et al. Late recurrent thymoma in myasthenia gravis: a case series. I Neurol Neurosurg Psychiatry. 2012;83:1030-1.

46. Margaritora S, Cesario A, Cusumano G, et al. Thirty-five-year follow-up analysis of clinical and pathologic outcomes of thymoma surgery. Ann Thorac Surg. 2010;89:245-52.

47. MCQuillen MP, Leone MG. A treatment carol: thymectomy revisited. Neurology. 1977;27:1103-6.

48. Oosterhuis HJ. Observations of the natural history of myasthenia gravis and the effect of thymectomy. Ann N Y Acad SCi. 1981:377:678-90.

49. Gronseth GS, Barohn RJ. Practice parameter thymectomy for autoimmune myasthenia gravis (an evidence-based review): report of the Quality Standards Subcommittee of the American Academy of Neurology. Neurology. 2000;55:7-15

50. Wolfe Gl, Kaminski HJ, Aban IB, et al. Randomized trial of thymectomy in myasthenia gravis. N Eng/ J Med. 2016;375:511-22.

51. Gajdos P, Chevret S, Toyka KV. Intravenous immunoglobulin for myasthenia gravis. Cochrane Database Syst Rev. 2012;12:CD002277

52. Gajdos $P$, Chevret $S$, Toyka K. Plasma exchange for myasthenia gravis. Cochrane Database Syst Rev. 2002;CD002275.

53. Benatar M, Sanders DB, Burns TM, et al. Recommendations for myasthenia gravis clinical trials. Muscle Nerve. 2012;45:909-17.

54. Drachman DB, Adams RN, Hu R, et al. Rebooting the immune system with high-dose cyclophosphamide for treatment of refractory myasthenia gravis. Ann N Y Acad SCi 2008:1132:305-14.

55. Gladstone DE, Brannagan $\mathrm{TH}$, 3rd, Schwartzman RJ, et al., High dose cyclophosphamide for severe refractory myasthenia gravis. J Neurol Neurosurg Psychiatry. 2004;75:789-91.

56. Strober J, Cowan MJ, Horn BN. Allogeneic hematopoietic cell transplantation for refractory myasthenia gravis. Arch Neurol. 2009;66:659-61.

57. Bryant $A, A$ Atkins $H$, Pringle $C E$, et al. Myasthenia gravis treated with autologous hematopoietic stem cell transplantation. JAMA Neurol. 2016;73:652-8.

58. Weiner GJ, Rituximab: mechanism of action. Semin Hematol. $2010: 47 \cdot 115-23$
59. Nowak RJ, Dicapua DB, Zebardast N, et al. Response of patients with refractory myasthenia gravis to rituximab: a retrospective study. Ther Adv Neurol Disord. 2011:4:259-66.

60. Lebrun C, Bourg V, Tieulie N, et al. Successful treatment of refractory generalized myasthenia gravis with rituximab. Eur J Neurol. 2009;16:246-50

61. Wylam ME, Anderson PM, Kuntz NL, et al. Successful treatment of refractory myasthenia gravis using rituximab: a pediatric case report. J Pediatr. 2003;143:674-7.

62. Zebardast N, Patwa HS, Novella SP, et al. Rituximab in the management of refractory myasthenia gravis. Muscle Nerve. 2010;41:375-8.

63. Tandan R, Hehir MK, 2nd, Waheed W, et al. Rituximab treatment of myasthenia gravis: a systematic review. Muscle Nerve. 2017:56:185-96

64. Jing S, Song Y, Song J, et al. Responsiveness to low-dose rituximab in refractory generalized myasthenia gravis. J Neuroimmunol. 2017:311:14-21.

65. Anderson D, Phan C, Johnston WS, et al. Rituximab in refractory myasthenia gravis: a prospective, open-label study with long-term follow-up. Ann Clin Trans/ Neurol 2016:3:552-5.

66. Robeson KR, Kumar A, Keung B, et al. Durability of the rituximab response in acetylcholine receptor autoantibody-positive myasthenia gravis. JAMA Neurol. 2017;74:60-6.

67. Diaz-Manera J, Martinez-Hernandez E, Querol L, et al. Long-lasting treatment effect of rituximab in MuSK myasthenia. Neurology. 2012;78:189-93.

68. Hehir MK, Hobson-Webb LD, Benatar M, et al. Rituximab as treatment for anti-MuSK myasthenia gravis: multicenter blinded prospective review. Neurology. 2017;89:1069-77.

69. Huda R, Tuzun E, Christadoss P. Targeting complement system to treat myasthenia gravis. Rev Neurosci. 2014:25:575-83.

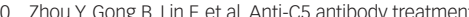
ameliorates weakness in experimentally acquired myasthenia gravis. J Immunol. 2007:179:8562-7.

71. Soltys J, Kusner LL, Young A, et al. Novel complement inhibitor limits severity of experimentally myasthenia gravis. Ann Neurol. 2009;65:67-75.

72. Rother RP, Rollins SA, Mojcik CF, et al. Discovery and development of the complement inhibitor eculizumab for the treatment of paroxysmal nocturnal hemoglobinuria. Nat Biotechnol. 2007;25:1256-64.

73. Howard JF, Jr., Barohn RJ, Cutter GR, et al. A randomized, double-blind, placebo-controlled phase II study of eculizumab in patients with refractory generalized myasthenia gravis. Muscle Nerve. 2013;48:76-84.

74. Business Wire, Alexion Pharmaceuticals, Inc. press release European Commission grants new indication for Soliris (eculizumab) for the treatment of patients with refractory generalized myasthenia gravis (gMG). Available at: https:// news alexion.com/press-release/product-news/europeancommission-grants-new-indication-soliris eculizumabtreatment-pa (accessed 23 October 2017).

75. Business Wire Alexion Pharmaceuticals Inc press release. FDA approves Soliris (eculizumab) for the treatment of patients with generalized myasthenia gravis (gMG). Available at: https:// news.alexionpharma.com/press-release/product-news/fdaapproves-soliris-eculizumab-treatment-patients-generalizedmyasthenia (accessed 5 March 2018).

76. Howard JF Jr., Utsugisawa K, Benatar M, et al. Safety and efficacy of eculizumab in anti-acetylcholine receptor antibody-positive refractory generalised myasthenia gravis (REGAIN): a phase 3, randomised, double-blind, placebo-controlled, multicentre study. Lancet Neurol. 2017;16:976-86

77. Schneider-Gold C, Reinacher-Schick A, Ellrichmann G, et al. Bortezomib in severe MuSK-antibody positive myasthen gravis: first clinical experience. Ther Adv Neurol Disord. 2017:10:339-41.

78. Frieri M, Heuser W, Bliss J. Efficacy of novel monoclona antibody belimumab in the treatment of lupus nephritis. J Pharmacol Pharmacother. 2015;6:71-6.

79. Gradolatto A, Nazzal D, Truffault F, et al. Both Treg cells and Tconv cells are defective in the myasthenia gravis thymus: roles of IL-17 and TNF-alpha. J Autoimmun. 2014;52:53-63.

80. Maurer M, Bougoin S, Feferman T, et al. IL-6 and Akt are involved in muscular pathogenesis in myasthenia gravis. Acta Neuropathol Commun. 2015;3:1.

81. Jonsson DI, Pirskanen R, Piehl F. Beneficial effect of tocilizumab in myasthenia gravis refractory to rituximab. Neuromuscul Disord. 2017:27:565-8.

82. Guptill JT, Soni M, Meriggioli MN. Current treatment, emerging translational therapies, and new therapeutic targets for autoimmune myasthenia gravis. Neurotherapeutics. 2016;13:118-31.

83. Sanders DB, Rosenfeld t. Dimachkie MM, et al.A

double-blinded, randomized, placebo-controlled trial to evaluate efficacy, safety, and tolerability of single doses of tirasemtiv in patients with acetylcholine receptor-binding antibody-positive myasthenia gravis. Neurotherapeutics. 2015;12:455-60

84. Ghazanfari N, Morsch M, Tse N, et al. Effects of the ss2-adrenoceptor agonist, albuterol, in a mouse model of anti-MUSK myasthenia gravis. PLoS One. 2014;9:e87840.

85. Evoli A, Alboini PE, Damato V, et al. 3,4-Diaminopyridine may improve myasthenia gravis with MUSK antibodies. Neurology. 2016;86:1070-1. 